\section{PL.30 FATHERS' EXPERIENCES OF PREGNANCY, LABOUR AND DELIVERY}

doi:10.1136/archdischild-2013-303966.213

A McHugh, MP Hehir, K Balla, M Foley, R Mahony. National Maternity Hospital, Holles street, Dublin, Dublin, Ireland

A fathers presence during labour is now commonplace in modern obstetric practise. We sought to evaluate fathers' experiences of pregnancy, labour and delivery. A survey was distributed to fathers in the postnatal period, and comprised of 17 questions. The questions were quantitative and multiple-choice in nature. No qualitative data was sought. A total of 1000 completed questionnaires were submitted for analysis. The mean age of fathers in the study was 33.8 years. Approximately $70 \%$ of the population were married, while $27.3 \%$ were in long term relationships. A significant percentage of the fathers were employed $(88.1 \%)$ in paid work. Less than $8 \%$ were unemployed. First time fathers constituted the largest group (53.7\%). Planned pregnancies constituted $77.9 \%$ with $2.5 \%$ as a result of fertility treatment. Seventy percent of fathers were 'overjoyed', $18.4 \%$ were 'pleased' and $11.3 \%$ responded either neutrally or negatively to the news of the pregnancy. Fathers were found to be likely to be present at ultrasound scans $(89.1 \%)$ but less likely to be involved in antenatal education classes (48\%). Almost all fathers were present at the delivery $(97.2 \%)$. Nearly half of the fathers $(49.6 \%)$ planned to attend the delivery because they really wanted to witness the birth, $43 \%$ attended to support their partner. At every stage of the pregnancy fathers perceived midwifery staff to have communicated better when compared to medical staff.

Our quantitative survey found that in general fathers involvement with the pregnancy process and their attendance at the birth to be a positive experience. Communication processes can be improved to better support the father in his role during this time.

\section{PL.31 A SIMPLE CLASSIFICATION SYSTEM FOR MATERNAL TRAUMATIC INJURIES ASSOCIATED WITH SECOND STAGE CAESAREAN SECTION}

doi:10.1136/archdischild-2013-303966.214

P Angala, M Raja, M Ikomi, R Varma. Basildon and Thurrock University Hospital, Basildon, UK

Background Caesarean section at full dilatation can be a technically demanding procedure and has a consistent association with laceration injuries to uterus, cervix and vagina. Recent Scottish Morbidity data showed $25 \%$ of women delivered by emergency caesarean section and experiencing massive obstetric haemorrhage $(\mathrm{MOH})$ were delivered in the $2^{\text {nd }}$ stage of labour. $16.3 \%$ of all the $\mathrm{MOH}$ cases were caused by extensions of the uterine incisions and/or broad ligament haematomas.

It is therefore surprising that to date a universally accepted formal classification system for maternal injuries (similar to that of obstetric anal sphincter injuries) relating to this scenario, is yet to emerge.

Aim To design a simple classification system and to apply this in a review of second stage deliveries at a UK University hospital

Method A retrospective analysis of the labour and operation notes of 60 patients delivered by caesarean section at full dilatation during a 9 month period in 2010. Uterine extensions were graded as: Grade 1 [easy to suture, no increase in operating time], Grade 2 [increased operating time and total blood loss] or Grade 3 [involvement of uterine artery, cervix, vagina, or bladder].

Results $25 \%[15 / 60]$ had uterine extensions of which $53 \%$ were Grade1, 27\% were grade 2 and $20 \%$ were grade 3 . It was easy to grade the extensions retrospectively. Grade 3 extensions resulted in longer operating times and higher blood transfusion rates.

Conclusion A simple classification of uterine extensions can improve the consistency of contemporaneous documentation and has potential as a research tool.

\section{PL.32 UMBILICAL ARTERY BLOOD ANALYSIS AT THE TIME OF DELIVERY: A COMPARISON BETWEEN BABIES BORN BY DIFFERENT MODES OF DELIVERY}

doi:10.1136/archdischild-2013-303966.215

1,2T Prior, 1,2E Mullins, 1.2P Bennett, 1,2S Kumar. 'Imperial College London, London, UK; ${ }^{2}$ Queen Charlotte's and Chelsea Hospital, London, UK

Introduction Umbilical cord arterial blood samples are taken routinely following delivery at many obstetric units in the UK. Whilst the $\mathrm{pH}$ of cord blood has been extensively investigated, other parameters have not. In this study we compared several parameters in cord blood between infants born by different modes of delivery.

Methods Umbilical artery cord blood samples taken immediately following delivery from 469 infants were analysed to compare $\mathrm{pH}$, base deficit, lactate, glucose, $\mathrm{p} 02$ and $\mathrm{pCO} 2$. These values were then compared using one-way ANOVA testing to determine if significant differences existed between the different mode of delivery groups.

Results Significant differences in the mean base excess, lactate, glucose and pO2 levels were observed between the different mode of delivery groups. Infants delivered by emergency Caesarean section for fetal compromise had the lowest $\mathrm{pO} 2$ and lowest glucose level of all mode of delivery groups, as well as the smallest base deficit and lowest lactate levels. No significant difference was observed in $\mathrm{pH}$ levels between the different mode of delivery groups.

Conclusions Umbilical artery $\mathrm{pH}$ at delivery is one mechanism used to evaluate the fetal condition at the time of delivery. We found no variation in umbilical artery $\mathrm{pH}$ between the different mode of delivery groups. This may have been due to resuscitative measures following the diagnosis of fetal compromise. However, despite this, significant differences in $\mathrm{p} 02$ and glucose levels remained. Further investigation of these parameters may allow better fetal assessment both intra-partum, and at the time of delivery.

\section{PL.33 CAN WE IMPROVE WOMEN'S OPERATIVE VAGINAL BIRTH EXPERIENCE?}

doi:10.1136/archdischild-2013-303966.216

${ }^{1} \underline{G}$ Cass, ${ }^{2} \mathrm{~K}$ Goyder, ${ }^{2 B}$ Strachan, ${ }^{2} \mathrm{R}$ Bahl. 'Musgrove Park Hospital, Taunton, UK; ${ }^{2}$ St Michaels Hospital, Bristol, UK

Background Obstetric practise is emotive, challenging and has long term impact both in terms of delivering new life but also for the mother where much of her experience occurs in labour and delivery.

Aim of this study To investigate the non-technical skills for operative vaginal delivery that have an impact on women's birth experience when having an OVD.

Method Sixteen women who had an OVD of a term baby underwent a semi structured interview 6-8 weeks postnatal. The interview recordings were transcribed verbatim. Thematic coding of data was carried out. Consistency of interpretation was ascertained by two researchers.

Results One of the key themes identified by women was a 'feeling of loss of control' and a 'need for explanation' of events to enable empowerment and reinforce control back to the woman. Women reported that 'loss of control is very worrying and overwhelming'. This want of ownership to the process of operative delivery is further highlighted by the "need for partnership 